\title{
Positioning Accuracy Analysis of Mapping and Surveying Satellite Using Laser Altimeter \\ Dou Qiang ${ }^{1}$, Li Yingbo ${ }^{2}$, Zhou Yu ${ }^{1}$, Cao Qipeng ${ }^{1}$, Zhu Jun $^{1}$ \\ ${ }^{1}$ DFH Satellite Co. Ltd, Beijing, 100094, China \\ ${ }^{2}$ Institute Of Space Mechanics \& Electricity, Beijing, 100094, China
}

Keywords: laser radar (Lidar), surveying and mapping, satellite, space camera

\begin{abstract}
The different mapping systems is analyzed in this paper, and as a way of acquiring elevation with high accuracy and effectiveness, laser altimeter can improve the capability of 3dimensional earth observation of satellite optical remote sensing imagery. And using high accuracy elevation observation of space-borne laser altimeter as control points accords with the trend of satellite photogrammetric without ground control points. In this paper, the problems of satellite photogrammetric are firstly introduced, and then the method of space-borne laser altimeter supported aero triangulation is described, which can solve these problems due to the characteristics of laser altimeter. The bundle adjustment error equations are established according to the earth observation of satellite image and space-borne laser altimeter, as well as the relationship of their exterior orientation elements. Elevation observations supplied by laser altimeter can be used as elevation control points to improve the accuracy of aero triangulation and the positioning accuracy. Finally, the improvement of elevation accuracy is shown by simulation using aero triangulation experiment of satellite image and space-borne laser altimeter, which can be improved from $9 \mathrm{~m}$ to $1.6 \mathrm{~m}$.
\end{abstract}

\section{Introduction}

The laser radar used in surveying and mapping is a popular in recent years in aerial photogrammetry field system. Laser radar data is used to obtain the elevation information and digital elevation model, and then through the multi-source data fusion, the realization of three-dimensional mapping can be achieved. The high accuracy of CCD camera plane positioning, high accuracy of laser radar elevation positioning, both information can effectively complement[1]-[4].

Airborne despite has higher precision, but limited in range. The high precision of mapping satellites can be used for large scale photogrammetric positioning and geographic data acquisition in the global range.[5] The system composition is complex, and engineering and technical difficulty is big. The current mapping satellite adopts double array / three line array CCD push-broom form of stereo images, satellite elevation control point laser measurement can obtain a large number of high precision synchronization of uniform distribution in the imaging stereo mapping camera time, avoid the difficult problems in some other areas. In the ground control surveying and mapping, elevation control points can be used as elevation redundant observation, improve the adjustment precision and stability; in the absence of control points or lack of control points, it can be directly used as control points, without ground control mapping.

\section{Index of high precision mapping satellite}

Performance parameters are directly related to the task of mapping satellite platform and make the following assumptions, the parameters such as shown in table 1 . 
Table 1 satellite and payload parameters for simulation

\begin{tabular}{|c|c|}
\hline Parameter name & Parameter \\
\hline Intersection angle $\left({ }^{\circ}\right)$ & $+6.5 /-25$ \\
\hline Orbit height $\quad(\mathrm{km})$ & 500 \\
\hline Base-height ratio & 0.59 \\
\hline Width $(\mathrm{km})$ & 60 \\
\hline Ground pixel resolution (m) & 2 \\
\hline Orbital speed(km/s) & 7.4 \\
\hline $\begin{array}{l}\text { Attitude pointing accuracy (including drift angle } \\
\text { control) }\end{array}$ & $\begin{array}{c}3 \text {-axis } \leq \\
0.03^{\circ}(3 \sigma)\end{array}$ \\
\hline Attitude stability (including drift angle control) & $\begin{array}{c}3 \text {-axis } \leq \\
0.0005^{\circ}(3 \sigma)\end{array}$ \\
\hline Accuracy of position $(\mathrm{m})$ & $\leq 0.1$ \\
\hline Accuracy of speed $(\mathrm{m} / \mathrm{s})$ & $\leq 0.05$ \\
\hline Laser height measurement accuracy（m) & $\leq 0.5$ \\
\hline Laser ground footprint $(\mathrm{m})$ & 10 \\
\hline Laser repetitive frequency $(\mathrm{Hz})$ & 2 \\
\hline
\end{tabular}

Spaceborne laser measurement system moves by its own movement of the satellite platform, and single laser beam divergence angle is designed as $0.02 \mathrm{mrad}$, then $500 \mathrm{~km}$ laser spot for $10 \mathrm{~m}$. Assuming the satellite flight rate is about $7.4 \mathrm{~km} / \mathrm{s}$, the laser repetition frequency is $2 \mathrm{~Hz}$, then each line of the laser spot minimum interval of about $3.7 \mathrm{~km}$.

\section{Analysis of positioning precision without control point}

\subsection{Analysis of plane positioning accuracy}

GPS positioning accuracy, star sensors and gyros attitude measurement accuracy, the synchronous time precision, platform stability, flight tremor factors such as the impact of measurement devices on satellite impact geometric positioning accuracy[6]-[8].

Assume that the errors are independent of each other, according to the error propagation law of linear array push broom CCD positioning sensor image precision estimation formula is as follows:

$$
\begin{aligned}
& \cos \psi_{x} \cdot m_{x}=\sqrt{\left(-\frac{f}{H}\right)^{2} m_{x_{s}}^{2}+f^{2} m_{\varphi}^{2}+f^{2}\left(\frac{y \cos \psi_{x}-f \sin \psi_{x}}{f \cos \psi_{x}+y \sin \psi_{x}}\right)^{2} m_{x}^{2}+m_{x_{0}}^{2}} \\
& \cos ^{2} \psi_{x} \cdot m_{y}=\sqrt{\begin{array}{l}
\left(-\frac{f}{H}\right)^{2} m_{Y_{s}}^{2}+\left(-\frac{y \cos \psi_{x}-f \sin \psi_{x}}{f \cos \psi_{x}+y \sin \psi_{x}} \frac{f}{H}\right)^{2} m_{z_{s}}^{2} \\
+f^{2}\left[1+\left(\frac{y \cos \psi_{x}-f \sin \psi_{x}}{f \cos \psi_{x}+y \sin \psi_{x}}\right)^{2}\right]^{2} m_{\omega}^{2}+m_{y_{0}}^{2}+\left(\frac{y \cos \psi_{x}-f \sin \psi_{x}}{f \cos \psi_{x}+y \sin \psi_{x}}\right)^{2} m_{f}^{2}
\end{array}}
\end{aligned}
$$

According to the error source and the corresponding analysis methods, the 1:25000 satellite mapping plane accuracy was analyzed, the results are as follows: 


\begin{tabular}{|c|c|c|c|c|c|c|}
\hline \multirow{2}{*}{\multicolumn{2}{|c|}{ Error source }} & \multirow[t]{2}{*}{$\begin{array}{l}\text { Chara } \\
\text { ct-erist } \\
\text { ic }\end{array}$} & \multicolumn{2}{|c|}{ Error } & \multicolumn{2}{|c|}{$\begin{array}{l}\text { Horizont } \\
\text { al } \\
\text { positioni } \\
\text { ng } \\
\text { accuracy } \\
\text { (m) }\end{array}$} \\
\hline & & & $\begin{array}{l}\text { Numeric } \\
\text { al }\end{array}$ & $\begin{array}{c}\text { Numerical } \\
\text { of } \mathrm{X} / \mathrm{Y} \\
\text { position }\end{array}$ & $\mathrm{m}_{\mathrm{X}}$ & $\mathrm{m}_{\mathrm{Y}}$ \\
\hline \multirow{7}{*}{$\begin{array}{l}\text { Orbit } \\
\text { error }\end{array}$} & \multirow{3}{*}{ GPS error } & \multirow{3}{*}{$\begin{array}{l}\text { Rando } \\
\text { m }\end{array}$} & \multirow{3}{*}{$0.1 \mathrm{~m}$} & $\begin{array}{c}\mathrm{m}_{\mathrm{Xs} 0}= \\
0.1 \mathrm{~m}\end{array}$ & 0.1 & 0 \\
\hline & & & & $\begin{array}{c}\mathrm{m}_{\mathrm{Ys} 0}= \\
0.1 \mathrm{~m}\end{array}$ & 0 & 0.1 \\
\hline & & & & $\begin{array}{c}\mathrm{m}_{\mathrm{Zs} 0}= \\
0.1 \mathrm{~m}\end{array}$ & 0 & 0 \\
\hline & \multirow{3}{*}{$\begin{array}{l}\text { Time } \\
\text { synchronization } \\
\text { error }\end{array}$} & \multirow{3}{*}{$\begin{array}{l}\text { Rando } \\
\text { m }\end{array}$} & \multirow{3}{*}{$\begin{array}{c}0.1 \mathrm{~ms} / 0 . \\
76 \mathrm{~m}\end{array}$} & $\begin{array}{r}\mathrm{m}_{\mathrm{Xs} 1}= \\
0.74 \mathrm{~m}\end{array}$ & $\begin{array}{c}0.7 \\
4\end{array}$ & 0 \\
\hline & & & & $\mathrm{m}_{\mathrm{Ys} 1}=0$ & 0 & 0 \\
\hline & & & & $\mathrm{m}_{\mathrm{Zs} 1}=0$ & 0 & 0 \\
\hline & \multicolumn{4}{|c|}{ Positioning error caused by orbit } & $\begin{array}{c}0.7 \\
5\end{array}$ & 0.1 \\
\hline \multirow{10}{*}{$\begin{array}{l}\text { Attitu } \\
\text { de } \\
\text { error }\end{array}$} & \multirow{3}{*}{$\begin{array}{l}\text { Star sensor } \\
\text { measurement } \\
\quad \text { error }\end{array}$} & \multirow{3}{*}{$\begin{array}{l}\text { Rando } \\
\text { m }\end{array}$} & \multirow{3}{*}{$0.67^{\prime \prime}$} & $\begin{array}{l}\mathrm{m}_{\square \square} \\
0.67^{\prime \prime}\end{array}$ & $\begin{array}{c}1.6 \\
2\end{array}$ & 0 \\
\hline & & & & $\mathrm{m}_{\square \square^{\prime \prime}}=$ & 0 & $\begin{array}{c}1.6 \\
2\end{array}$ \\
\hline & & & & $\begin{array}{c}\mathrm{m}_{\square} \\
0.67^{\prime \prime}\end{array}$ & 0 & 0 \\
\hline & \multirow{3}{*}{$\begin{array}{l}\text { Installation } \\
\text { error between } \\
\text { star sensor and } \\
\text { camera }\end{array}$} & \multirow{3}{*}{$\begin{array}{l}\text { Calibr } \\
\text { ation }\end{array}$} & \multirow{3}{*}{$\begin{array}{c}\text { Instrume } \\
\text { nt } \\
\text { accuracy } \\
0.5^{\prime \prime}\end{array}$} & $\mathrm{m}_{0.5^{\prime \prime}}=$ & $\begin{array}{c}1.4 \\
6\end{array}$ & 0 \\
\hline & & & & $\mathrm{m}_{0 . \square^{\prime \prime}}=$ & 0 & $\begin{array}{c}1.4 \\
6\end{array}$ \\
\hline & & & & $\begin{array}{c}\mathrm{m}_{\square^{\prime} \overline{5}^{\prime \prime}} \\
=\end{array}$ & 0 & 0 \\
\hline & \multirow{3}{*}{$\begin{array}{c}\text { Camera } \\
\text { pointing error } \\
\text { caused by } \\
\text { thermal } \\
\text { environment }\end{array}$} & \multirow{3}{*}{$\begin{array}{l}\text { Rando } \\
\text { m }\end{array}$} & \multirow{3}{*}{$3 "$} & $\mathrm{~m}_{\square \square}=3^{\prime \prime}$ & $\begin{array}{c}7.0 \\
7\end{array}$ & 0 \\
\hline & & & & $\mathrm{m}_{\square \square}=3^{\prime \prime}$ & 0 & $\begin{array}{c}7.0 \\
7\end{array}$ \\
\hline & & & & $\mathrm{m}_{\square \square}=3^{\prime \prime}$ & 0 & 0 \\
\hline & \multicolumn{4}{|c|}{ Positioning error caused by attitude } & $\begin{array}{c}7.4 \\
0\end{array}$ & $\begin{array}{c}7.4 \\
0\end{array}$ \\
\hline \multirow{4}{*}{$\begin{array}{l}\text { Optic } \\
\text { al } \\
\text { syste } \\
\text { m } \\
\text { error }\end{array}$} & \multirow{3}{*}{$\begin{array}{l}\text { Elements of } \\
\text { interior } \\
\text { orientation } \\
\text { calibration } \\
\quad \text { error }\end{array}$} & \multirow{3}{*}{$\begin{array}{l}\text { Calibr } \\
\text { ation }\end{array}$} & \multirow{3}{*}{$\begin{array}{l}\text { Main } \\
\text { points } \\
\text { accuracy } \\
0.3 \text { pixel }\end{array}$} & $\begin{array}{c}\mathrm{m}_{\mathrm{x} 0}=2.1 \mu \\
\mathrm{m}\end{array}$ & $\sim 0$ & 0 \\
\hline & & & & $\begin{array}{c}\mathrm{m}_{\mathrm{y} 0}=2.1 \mu \\
\mathrm{m}\end{array}$ & 0 & $\sim 0$ \\
\hline & & & & $\mathrm{m}_{\mathrm{f} 0}=20 \mu \mathrm{m}$ & 0 & 0 \\
\hline & \multicolumn{4}{|c|}{ Positioning error caused by camera } & 0 & 0 \\
\hline & \multirow{2}{*}{\multicolumn{4}{|c|}{ Totally positioning error }} & $\begin{array}{c}7.4 \\
0 \\
\end{array}$ & $\begin{array}{c}7.4 \\
0 \\
\end{array}$ \\
\hline & & & & & \multicolumn{2}{|c|}{10.5} \\
\hline
\end{tabular}

Table 2 Analysis of planar positioning accuracy

Double line array mapping camera plane positioning accuracy of about $10.5 \mathrm{~m}$, with no control point conditions can meet the requirements better than $15 \mathrm{~m}$.

\subsection{Analysis of elevation accuracy}

No control point case constitute the height precision needs under the disparity, therefore before and after viewing is constitution three-dimensional foundation, the intersection accuracy depends on 
the stereo in baseline error, in the along track direction angle precision, pitch based high (rendezvous angle) and other factors.

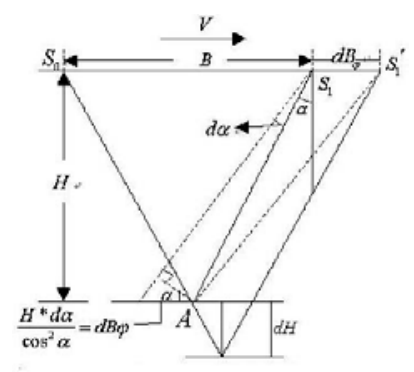

Fig. 1 Schematic diagram of the accuracy of elevation effect

The attitude angle error is an important factor affecting the height precision, the influence of $d \alpha$ on the height as shown in figure 1.

In the case of no ground control points, two rays of rendezvous and elevation error:

$$
d h_{\alpha}=2 \frac{H}{B} \cdot \frac{H \cdot d \alpha}{\cos ^{2} \alpha} \quad(\alpha \text { is the pitch angle }) \text { 。 }
$$

The formula above is in no side swing analysis case, if there is a side of the pendulum, then

$$
d h_{\alpha}=2 \frac{H}{B} \cdot \frac{H \cdot d \text { pitch }}{\cos \alpha \cos \text { pitch }}
$$

Influence of satellite line elements $\mathrm{X}$ and $\mathrm{Z}$ direction error of elevation is $\delta_{H}^{2}+\left(\frac{H}{B}\right)^{2} \delta_{B}^{2}$;

The image point measurement error is $\left(\frac{H}{B}\right)^{2} \delta_{p}^{2}$;

Effects of yaw angle error of elevation is $\left(\frac{\sqrt{2}}{2} \frac{H}{B} y\right)^{2} \delta_{\text {yaw }}^{2}$.

When the method, through internal and external calibration eliminates both inside and outside the system error of satellite platform, elevation error comes mainly from the orbit height error $\delta_{H}$, baseline error $\delta_{B}$, image point measurement elevation error $\delta_{p}$ caused by the attitude angle error, the elevation error $\delta_{\alpha}$ caused by attitude angle error. The calculation formula is as follows:

$$
\delta_{h}^{2}=\delta_{H}^{2}+\left(\frac{H}{B}\right)^{2} \delta_{B}^{2}+\left(\frac{H}{B}\right)^{2} \delta_{p}^{2}+\left(\frac{2 H^{2}}{B \cos \alpha \cos p i t c h}\right)^{2} \delta_{\text {pitch }}^{2}+\left(\frac{\sqrt{2}}{2} \frac{H}{B} y\right)^{2} \delta_{\text {yaw }}^{2}
$$

The edge pixel set a ground point imaging line array CCD. Table 3, by using the ground point coordinates of all internal and external orientation elements of the partial derivative calculation results, calculate the elevation error on the positioning of the forward-looking image and rearview image.

Under no control condition, the target localization accuracy depends on all error sources. The error into account, to get the target positioning precision. Twin line array mapping camera in the elevation direction of ground target positioning precision of:

$$
m_{z}=8.98 m
$$

\section{Analysis of positioning precision based on laser measuring}

\subsection{Laser radar and double array combined adjustment model}

With 4 accuracy is better than 0.1M GPS ground points as control points, the other 14 point GPS as the check point, on the satellite image was empty three mapping, plane precision of $2.93 \mathrm{M}$ is obtained, the accuracy of elevation is $2.07 \mathrm{~m}$. The results show that, at present, for the high resolution remote sensing satellite images, need only a few high precision control point positioning accuracy can be obtained observations need. 


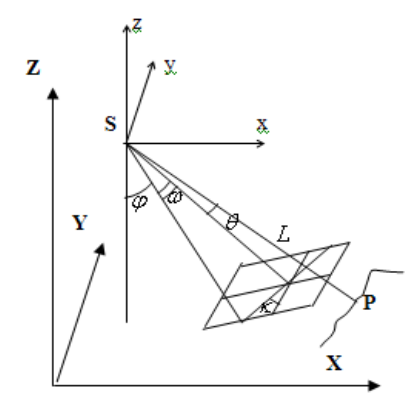

Fig. 2 Schematic diagram of laser range finder positioning

In practical application, can be in stereo mapping camera placement of two measuring laser measuring, with a certain frequency of the transmitted beam, can obtain higher accuracy in elevation points at both ends of the distribution of image. Or the installation of multi beam laser measuring, get elevation points uniformly distributed in the camera imaging area. Below is a schematic diagram of two kinds of laser measuring assistant surveying and mapping scheme, the black circles denote the laser measuring Grohespot footprints.
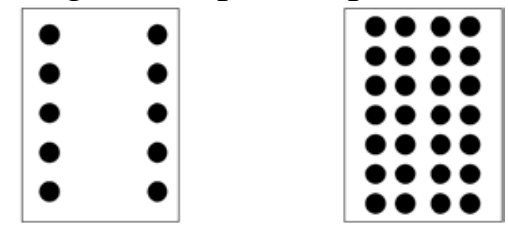

Fig. 3 Lidar elevation control points distribution

Laser measuring comparing with mapping camera , error propagation coefficient of external azimuth elements on the elevation coordinates is only one of dozens. The laser altimeter data and the reference DEM, improve the accuracy of laser measuring levels, in the same auxiliary orientation parameters under the condition of laser altimeter observation, can significantly improve the accuracy of elevation of earth observation.

Satellite image photogrammetry measurement equation is as follows

$$
\left[\begin{array}{l}
X_{P} \\
Y_{P} \\
Z_{P}
\end{array}\right]=\left[\begin{array}{l}
X_{S P} \\
Y_{S P} \\
Z_{S P}
\end{array}\right]+\lambda\left[\begin{array}{lll}
a_{1 p} & a_{2 p} & a_{3 p} \\
b_{1 p} & b_{2 p} & b_{3 p} \\
c_{1 p} & c_{2 p} & c_{3 p}
\end{array}\right]\left[\begin{array}{l}
x \\
y \\
-f
\end{array}\right]
$$

Grohe laser measurement of earth observation equation is as follows

$$
\left[\begin{array}{l}
X_{L} \\
Y_{L} \\
Z_{L}
\end{array}\right]=\left[\begin{array}{l}
X_{S L} \\
Y_{S L} \\
Z_{S L}
\end{array}\right]+\lambda\left[\begin{array}{lll}
a_{1 L} & a_{2 L} & a_{3 L} \\
b_{1 L} & b_{2 L} & b_{3 L} \\
c_{1 L} & c_{2 L} & c_{3 L}
\end{array}\right]\left[\begin{array}{l}
0 \\
\sin \theta \\
\cos \theta
\end{array}\right]
$$

In the formula(XP,YP,ZP), (XL,YL,ZL)were ground coordinate mapping camera and laser measuring observations; (XSP,YSP,ZSP), (XSL,YSL,ZSL) is outside the range of line element; (a1P,a2P,a3P, b1P,b2P,b3P, c1P,c2P,c3P), (a1L,a2L,a3L, b1L,b2L,b3L, c1L,c2L,c3L)for external azimuth element direction cosine; $(\mathrm{x}, \mathrm{y}, \mathrm{f})$ for the azimuth element mapping camera; $\lambda$ as the zoom scale; $\mathrm{L}$ is the laser range value; $\theta$ is laser measuring pointing angle.

\subsection{Laser ranging assisted photogrammetry elevation error}

The laser ranging data for photogrammetric processing can be carried out in accordance with relatively simple way, namely the use of laser ranging correction elevation error, its role as shown in figure 4. 


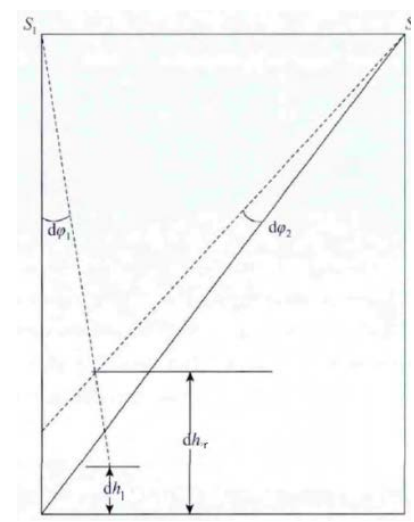

Fig. 4 Effect of laser ranging in elevation accuracy.

In Fig. 4, d $\phi 1$ d $\phi 2$ is satellite angular error in the pitch direction in S1, S2 moment; dhr (rendezvous) is error using S1, S2 moment of the image directly intersection; dhl(Laser) is a laser ranging error of S1 moments. Using laser range points can be minimal dhr. Intersection height error for arbitrary laser point

$$
d h_{k}=d h_{k m}+d h_{k r}
$$

laser points $\mathrm{k}=1,2,3, \ldots \mathrm{m}$; $d h_{k r}$ rendezvous error can be regarded as a constant value; $d h_{k m}$ matching for two line array images matching elevation error.

Using the front elevation and elevation of laser ranging intersection comparison can have poor value

$$
\Delta=d h_{k}-d h_{k l}=d h_{k m}-d h_{k l}+d h_{k r}
$$

The $\mathrm{M}$ laser point data and make appropriate adjustment, average simple can get

$\bar{\Delta}=\overline{d h_{k m}}-\overline{d h_{k l}}+\overline{d h_{k r}}$

In order to correct the measuring height of any point within the area, elevation error for arbitrary point:

$$
d h_{i} \approx d h_{k m}+\overline{d h_{k r}}, i=1,2,3, \ldots \ldots, n
$$

From equation (4) shows: by multiple laser point data, can effectively improve the accuracy of ground elevation

Without ground control point photogrammetry, stereo mapping needs exterior orientation elements of exterior orientation elements can participate in, before using, rearview image observations according to the intersection to determine the coordinates of ground points. The estimation formula can be simplified by using the elevation error, and is divided into image matching error and angle rendezvous error two.

$$
\sigma h_{r}=\frac{H}{B} \times \frac{\sqrt{2} \times H}{\cos ^{2} \alpha} \times \sigma \varphi
$$

$\mathrm{H}$ is the height of satellite orbit; $\mathrm{B}$ as the baseline length; $\sigma \varphi$ is forward-looking or camera angle of light. Calculated elevation error is

$$
d h_{k r}=\left\{\begin{array}{l}
5.6 m, \sigma \varphi=0.7 " \\
8.1 m, \sigma \varphi=1 " \\
16.2 m, \sigma \varphi=2 "
\end{array}\right.
$$

$\sigma \mathrm{h}$ rendezvous is greatly influenced by $\sigma \varphi$, which is the key problem of dynamic photography stereo intersection accuracy, $\sigma \varphi$ changes 1", the accuracy of elevation change of about $8.1 \mathrm{~m}$, attitude change is affecting the accuracy of positioning (especially the elevation accuracy) of the important factors.

Image matching error and the rendezvous error related, as shown in the following formula.

$\sigma_{r}=\frac{H}{B} \times 0.3 \times \mathrm{GSD}$

The base-height ratio is 0.59 , GSD is $2 \mathrm{~m}$, then

$$
d h_{k r}=\left\{\begin{array}{l}
2.5 m, \sigma \varphi=5 m \\
1 m, \sigma \varphi=2 m \\
0.5 m, \sigma \varphi=1 m
\end{array}\right.
$$


Laser with a $2 \mathrm{~Hz}$ output images per second, 10 vertical control point, get the adjustment results as follows:

$d h_{l}=0.5 \mathrm{~m}$

$d h_{i}=1.6 m$

Finally, the accuracy of elevation adjustment can reach $1.6 \mathrm{~m}$, which can meet the needs of 1:2.5 million scale map.

\section{Conclusions}

In this paper, for 1:2.5 million scale surveying and mapping, before the use of laser radar case, plane positioning precision without control point absolute positioning is $10.5 \mathrm{~m}$, which can satisfy the requirements $15 \mathrm{~m}$, but the elevation accuracy without laser control point is $8.98 \mathrm{~m}$, can not meet the demand of the accuracy of elevation mapping $3 \mathrm{~m}$. Through the introduction of laser radar altimetry and calculated, can let the height accuracy of $1.6 \mathrm{~m}$ which is better than $3 \mathrm{~m}$. The results shows that elevation observations supplied by laser altimeter can be used as elevation control points to improve the accuracy of aero triangulation and the positioning accuracy.

\section{References}

[1] Sungkoo Bae, Charles Web, Bob Schutz. GLAS PAD Calibration Using Laser Reference Sensor Data[C]. In AIAA/AAS Astrodynamics Specialist Conference and Exhibit, Providence, RI, USA, 2004: 1-10.

[2] Archinal B A,Rosiek M R,Kirk R L,et al.The unified lunar control network 2005. U.S.Geological Survey Open File Report2006-1367, Version1.0.

[3] Luthcke S B,Rowlands DD,Williams T A, et al. Reduction of ICESat systematic geolocation errors and the impact on ice sheet elevation change detection. Geophysical Research Letters . 2005

[4] LIGHTD L.Characteristics of remote sensors for map-ping and earth science applications. Photogrammetric Engineering\&Remote Sensing . 1990

[5] GRUEN A,ZHANG L.3D Processing of High Resolution Satellite Images. Busan,Asian Conference on Remote Sensing 2003 . 2003

[6] Takanori Iwata.Precision Attitude and Position Determination for the Advanced Land Observing Satellite(ALOS). Enabling Sensor and Platform Technologies for Space-borne Remote Sensing . 2005

[7] WANG Renxiang. Summary of satellite photogrammetry without ground control point. [J]. Osean surveying and mapping, 2008, 28 (5):1-8

[8] YU Junpeng. Study on error propagation azimuth of the satellite remote sensing image elements. Space return and remote sensing, 2011, 32 (1): 18-23. 